\title{
Fatores de virulência de Staphylococcus aureus
}

\author{
[Staphylococcus aureus virulence factors]
}

\section{"Revisão/Review"}

\section{Atzel Candido Acosta ${ }^{1 *}$, Mateus Matiuzzi Costa ${ }^{2}$, José Wilton Pinheiro Junior ${ }^{1}$, Rinaldo Aparecido Mota ${ }^{1}$}

\author{
${ }^{1}$ Laboratório de Bacterioses dos Animais Domésticos, Departamento de Medicina Veterinária, Universidade Federal \\ Rural de Pernambuco, Recife-PE, Brasil. \\ ${ }^{2}$ Universidade Federal do Vale do São Francisco (Univasf), Petrolina-PE, Brasil. \\ *Autor para correspondência/Corresponding author: E-mail: acabad80@gmail.com
}

\section{Resumo}

Nas últimas décadas, Staphylococcus aureus (S. aureus) adquiriu considerável importância relacionada à saúde animal e humana pela elevada patogenicidade e aumento na prevalência de cepas multirresistentes aos antibióticos. Sua elevada patogenicidade está relacionada com mecanismos multifatoriais e complexos determinados pela capacidade da bactéria de expressar uma variedade de fatores de virulência que facilitam a ocorrência de doenças. Objetivou-se com esta revisão compilar informações referentes aos fatores de virulência associados à superfície ou secretados por $S$. aureus que promovem adesão aos componentes da matriz extracelular do hospedeiro, danificam células hospedeiras e interferem no sistema imunológico. A implementação de estratégias para a prevenção e terapia em infecções associadas a $S$. aureus exige o aprofundamento dos estudos nos diferentes mecanismos de ação dos fatores de virulência.

Palavras-Chave: micro-organismo; aderência; toxinas hemolíticas; saúde animal; biofilme.

\begin{abstract}
In the last decades, Staphylococcus aureus (S. aureus) acquired a dramatic relevance in human and veterinary medicine by the high pathogenicity and increasing prevalence of antibiotic resistant strains. Its high pathogenicity is driven by multifactorial and complex mechanisms determined by the ability of the bacterium to express a wide variety of virulence factors that facilitate the infection. The aim of this review was to compile information about $S$. aureus secreted or cell surface-associated virulence factors that promote adhesion to the host extracellular matrix components, damage host cells, and fight the immune system. The successful implementation of preventatives and therapeutics strategies in $S$. aureus infection will require an integrated understanding of the molecular pathogenesis of principal virulence factors and an appreciation of the immunologic responses that confer protection.
\end{abstract}

Keywords: microorganism; adhesins; hemolytic toxin; animal health; biofilm.

\section{Introdução}

Staphylococcus aureus (S. aureus) apresenta uma marcada capacidade para se adaptar a diferentes condições ambientais e representa um importante agente causador de doenças infeciosas em humanos e animais (Hasman et al., 2010; AlDabbagh e Dobson 2011; Fluit 2012). Este microorganismo produz vários fatores de virulência que promovem adesão aos componentes da matriz extracelular do hospedeiro, danificam suas células e protegem a bactéria do sistema imunológico (Foster 2005; Zecconi e Scali 2013).

Os fatores de virulência, já descritos no mínimo 15 para $S$. aureus, são componentes de superfície microbiana que reconhecem as moléculas da matriz extracelular do hospedeiro, 25 toxinas e 20 moléculas de evasão do sistema imune do hospedeiro (Fluit, 2012). A adesão de $S$. aureus às proteínas da matriz extracelular do hospedeiro, 
como fibrinogênio, fibronectina e colágeno é importante para iniciar a infeção. Esta adesão é mediada por proteínas associadas à parede da célula bacteriana chamadas MSCRAMMs (Microbial Surface Components Recognizing Adhesive Matrix Molecules) que estão ancoradas por uma ligação covalente ao peptidoglicano pela ação de uma transpeptidase denominada sortase (Navarre e Schneewind 1994; Mazmanian et al., 1999).

A maioria dos isolados de $S$. aureus secreta um grupo de enzimas e citotoxinas que incluem as toxinas hemolíticas, nucleases, proteases, lipases, hialuronidase e colagenase. A principal função destas enzimas e citotoxinas seria a conversão dos tecidos dos hospedeiros em nutrientes necessários para o crescimento bacteriano (Dinges et al., 2000). Um número significativo de isolados obtidos de animais são produtores de outras exotoxinas como a toxina da síndrome do choque tóxico e enterotoxinas (Sá et al., 2004; Lamaita et al., 2005; Carfora et al., 2015).

A capacidade de resistir à fagocitose é um importante fator que favorece a progressão da infecção por esta bactéria. Mediante a expressão de proteínas anti-opsônicas associadas à superfície e uma cápsula de polissacarídeo que interfere com a deposição de anticorpos e a formação de complemento por vias clássicas e alternativas que dificulta a fagocitose desta bactéria (Foster, 2005). A capacidade de formar biofilme em isolados de $S$. aureus aumenta a complexidade das infecções (Melchior et al., 2006). O biofilme é uma eficiente estratégia de evasão imunológica pelo bloqueio físico (Thurlow et al., 2011). As bactérias em biofilmes também são menos sensíveis ao tratamento com agentes antimicrobianos (Costerton, 1995), o que colabora na manutenção das infecções crônicas.

Nesta revisão, objetivou-se compilar informação dos fatores de virulência associados à superfície ou secretada por $S$. aureus que promovem adesão aos componentes da matriz extracelular do hospedeiro, danificam as células do hospedeiro e protegem a bactéria do sistema imunológico.

\section{Proteína fibrolectina ligante (Fnbs do inglês Fibronectin-binding protein)}

A adesão é o pré-requisito para a colonização e o desenvolvimento de uma eventual infecção no hospedeiro. S. aureus sintetiza duas proteínas fibronectina ligantes homólogas: FnbA e
FnbB (Shinji et al., 2011). Estas proteínas são codificadas por dois genes estreitamente ligados e após 682pb do códon de parada do fnbA, inicia-se o domínio S do gene $f n b B$ (Jönsson et al., 1991). O gene $f n b A$ é formado por $3057 \mathrm{pb}$ distribuídos em sete regiões (Figura 1), codifica 1018 aminoácidos e tem como códon de parada o TAA. Foram identificadas três regiões repetidas no gene $f n b A$ : a região $\mathrm{B}$ com 30 aminoácidos repetidos $\left(\mathrm{B}_{1}, \mathrm{~B}_{2}\right)$, a região $\mathrm{D}$ com 38 aminoácidos repetidos três vezes e parcialmente repetido uma quarta vez $\left(D_{1}-D_{4}\right)$ e a região $\mathrm{Wr}$ em que 14 aminoácidos são repetidos cinco vezes $\left(\mathrm{Wr}_{1}-\mathrm{Wr}_{5}\right)$ (Signäs et al., 1989).

$\mathrm{O}$ gene $f n b B$ apresenta boa parte da sequência homóloga ao gene $f n b A$. Constatou-se que $94 \%$ dos aminoácidos da região sinal (S) são idênticos entre as duas adesinas. A partir da região espaçadora (C), 94\% dos aminoácidos são idênticos entre ambas as proteínas. O gene $f n b B$ não tem a região repetida B (Jönsson et al., 1991).

Estas adesinas (FnbA e FnbB) são as duas proteínas de grande importância na fase inicial de adesão nos processos infeciosos por $S$. aureus $(\mathrm{Hu}$ et al., 2010) e se ligam à fibronectina e a elastina, a FnbA também pode se ligar ao fibrinogênio (Peacock et al., 2002; Clarke e Foster 2006; Chavakis et al., 2007; Speziale et al., 2009). A fibronectina é uma glicoproteína de $440 \mathrm{kDa}$ presente no hospedeiro na forma solúvel no sangue e na forma fibrosa nas matrizes celulares. É importante, pois permite a adesão bacteriana a esta proteína em diferentes momentos do processo infeccioso (Patti et al., 1994). Por outro lado, dois grupos de pesquisadores independentes descreveram novos fenótipos de biofilmes de $S$. aureus mediados pelas proteínas FnbA e FnbB (O'Neill et al., 2008; Shanks et al., 2008).

\section{Fator de agrupamento (Clfs do inglês Clumping factor)}

Os genes clfA e clfB não são variantes alélicos, mas sim genes diferentes (Foster e Höök 1998). A ClfA está presente em todas as fases do crescimento de $S$. aureus e a ClfB está presente na fase exponencial de crescimento da bactéria em condições de anaerobiose (Ní Eidhin et al., 1998). A estrutura organizacional das adesinas ClfA e ClfB é similar às outras proteínas de superfície ancoradas na parede celular como a FnbA (Figura 1). Um aspecto distinto destas adesinas é a presença do domínio R que consiste em uma longa região de dipeptídeo Asp-Ser repetida que conecta a região espaçadora A e o domínio da extensão da 
membrana $\mathrm{M}$, estando este domínio presente em ambas as adesinas (Foster e Höök, 1998).

\begin{tabular}{|l|l|l|l|l|l|l|l|l|l|l|l|}
\hline $\mathrm{S}$ & $\mathrm{A}$ & $\mathrm{B}_{1}$ & $\mathrm{~B}_{2}$ & $\mathrm{C}$ & $\mathrm{D}_{1}$ & $\mathrm{D}_{2}$ & $\mathrm{D}_{3}$ & $\mathrm{D}_{4}$ & $\mathrm{Wr}$ & $\mathrm{Wc}$ & $\mathrm{M}$ \\
\hline
\end{tabular}

Figura 1. Diagrama esquemático das diferentes regiões do gene fnbA (Signäs et al., 1989). S sequência sinal, A e $\mathrm{C}$ regiões espaçadora, $\mathrm{B}$ e $\mathrm{D}$ regiões diferentes repetidas fora do domínio da parede celular, $\mathrm{Wr}$ região repetida do domínio da extensão da parede celular, Wc região não repetida do domínio da extensão da parede celular e M domínio da extensão da membrana.

As ClfA e ClfB se ligam ao fibrinogênio e promovem a agregação das plaquetas (Peacock et al., 2002; Clarke e Foster 2006; Speziale et al., 2009). No entanto, a fibrina solúvel parece ser a principal proteína responsável pela formação de agregados de plaquetas mediados pelas proteínas Clfs de S. aureus (Niemann et al., 2004). O ClfB também tem a capacidade de se ligar à citoqueratina 10 (Clarke e Foster 2006; Speziale et al., 2009) e à citoqueratina 8 (Haim et al., 2010).

Muitas moléculas que participam na adesão também estão envolvidas em diferentes mecanismos de evasão imunológica. Por exemplo, a ativação do sistema complemento é prejudicada por algumas destas adesinas. O ClfA se liga ao fator regulador do complemento 1 (C1) aumentando a conversão de $\mathrm{C} 3 \mathrm{~b}$ para uma forma inativada (iC3b) e prejudicando a fagocitose de S. aureus (Hair et al., 2010).

\section{Toxinas hemolíticas}

Inicialmente estas toxinas foram denominadas desta forma tendo como base a sua propriedade de causar a lise de eritrócitos. $\mathrm{O}$ ferro é um nutriente limitante para todos os organismos, sendo necessário em muitos processos biológicos. Um papel proposto para as hemolisinas bacterianas é a liberação do grupo heme presente na hemoglobina e mioglobina dos eritrócitos (Huseby et al., 2007). S. aureus tem um sistema múltiplo de componentes que permite importar o grupo heme e extrair o ferro (Torres et al., 2006). As toxinas alfa, beta, delta e gama são produzidas por diferentes isolados de $S$. aureus com efeito citotóxico frente a várias células do hospedeiro, incluindo as imunológicas (Dinges et al., 2000).

\section{Toxina $\alpha$ hemolítica ou $\alpha$ toxina (Hla)}

O gene que codifica para esta toxina ( $h l a$ ) foi descrito em 1980, por meio da metodologia de recombinação de fagos que transferiu a habilidade de lisar células vermelhas às $E$. coli (Kehoe et al., 1983). O locus hla está constituído por 1620 nucleotídeos (Fairweather et al., 1983) e codifica para 319 aminoácidos (Gray e Kehoe, 1984), sendo secretada como um monômero solúvel em água (Song et al., 1996). Após o processo de amadurecimento extracelular, a toxina perde 26 aminoácidos sendo esta sua forma ativa de aproximadamente $33 \mathrm{kDa}$ (Tweten et al., 1983). A expressão da Hla é controlada por diferentes sistemas de regulação global (Recsei et al., 1986). Estes circuitos de regulação permitem o controle rigoroso da expressão da $\mathrm{Hla}$ in vivo $\mathrm{e}$ provavelmente facilitam uma resposta rápida e específica às mudanças das condições do meio (Berube e Wardenburg, 2013).

Por muito tempo, a atividade da $\mathrm{Hla}$ concentrou os debates na alta suscetibilidade da lise de eritrócitos de coelho frente à relativa não sensibilização dos eritrócitos humanos (Cassidy e Harshman, 1973/1976; Hildebrand et al., 1991). Nos últimos anos, a ADAM10 (A Disintegrin And Metalloprotease 10) foi assinalada como um proteináceo receptor do Hla (Wilke e Wardenburg, 2010), sustentado pelos seguintes achados: (1) ADAM10 da membrana das células do hospedeiro é precipitada pela Hla, (2) ADAM10 é requerida para a construção da toxina e sua oligomerização e a exigência de ADAM10 na citotoxicidade mediada por Hla é maior em baixas concentrações de toxina onde se prevê a necessidade de um receptor celular de alta afinidade (Cassidy e Harshman, 1976), (3) a atividade hemolítica espécie específica exigida pela Hla está associada à expressão da ADAM10 em eritrócitos de coelhos em contraste com a ausência na superfície dos eritrócitos de humanos (Wilke e Wardenburg, 2010).

A $\alpha$ toxina é considerada a mais importante citotoxina produzida por $S$. aureus, pois é capaz de atuar contra uma gama de células do hospedeiro como por exemplo eritrócitos, células epiteliais, células endoteliais, linfócitos $\mathrm{T}$, monócitos e macrófagos (Berube e Wardenburg, 2013). Considera-se que esta pode apresentar um importante papel na patogenia das infeções ocasionadas por este agente, sendo esta afirmação sustentada por duas linhas de evidências. Em primeiro lugar, os hospedeiros acometidos por doenças causadas por $S$. aureus desenvolvem uma resposta de anticorpos séricos à Hla relacionada ao grau de expressão da toxina (Kolata et al., 2011; Adhikari et al., 2012; Fritz et al., 2013). Indivíduos 
com risco de septicemia por $S$. aureus apresentaram uma diminuição desse risco em indivíduos com altos títulos de anticorpos séricos contra Hla e outras quatro toxinas de S. aureus (Adhikari et al., 2012). A segunda linha de evidência está fundamentada em estudos de genética microbiana e da análise do perfil proteico. A linhagem $S$. aureus denominada "Phage-type $80 / 81$ " foi muito importante nas epidemias durante as décadas 1950-1960, sendo caracterizada como altamente virulenta. Quando foram estudados os loci hla e agr (Accessory Gene Regulator) da linhagem Phage-type 80/81 constatou-se a capacidade de expressão da Hla e produção de infeções mediadas por esta toxina. Já no caso da linhagem EMRSA-16 e seus clones associados observou-se mutações pontuais em ambos loci, o que impediu a produção da Hla e reduziu a virulência desta linhagem (DeLeo et al., 2011).

\section{Toxina $\beta$ hemolítica ou $\beta$ toxina $(\mathrm{Hlb})$}

A toxina $\beta$ hemolítica foi identificada em 1935 por Glenny e Stevens (1935). É uma esfingomielinase $\mathrm{C}$ dependente de $\mathrm{Mg}^{2+}$ que degrada a esfingomielina presente na membrana celular de eritrócitos, leucócitos, neurônios e outros tipos de células, causando lise (Bernheimer et al., 1974; Dinges et al., 2000). O gene hlb foi identificado, clonado e sequenciado em 1989, sendo Hlb sintetizada como uma proteína de $39 \mathrm{kDa}$ de 330 aminoácidos (Projan et al., 1989); posteriormente é clivada e excretada na forma ativa de $35 \mathrm{kDa}$ (Dinges et al., 2000). Quando foi identificada a sequência de nucleotídeo e consequentemente a sequência de aminoácidos observou-se que existia $55,7 \%$ de similaridade com a sequência de 200 aminoácidos da esfingomielinase de Bacillus cereus (Projan et al., 1989).

A $\beta$ toxina também é conhecida como a toxina quente-frio, pois a $37^{\circ} \mathrm{C}$ interage com as células vermelhas do sangue de ovelha, mas não as lisam. Se os glóbulos vermelhos são colocados a $4^{\circ} \mathrm{C}$, as células são lisadas. Isto é observado pela ausência de hemólise em placas de ágar sangue a $37^{\circ} \mathrm{C}$ e depois uma hemólise completa a $4^{\circ} \mathrm{C}$ (Huseby et al., 2007).

A $\beta$ toxina é produzida pela maioria dos isolados de $S$. aureus associados às mastites bovinas (Aarestrup et al., 1999) e infeções crônicas da pele de humanos (Katayama et al., 2013). O estudo de Huseby et al. (2007) sobre mutações no sítio ativo da Hlb demonstraram que a atividade hemolítica e linfotoxicidade estão relacionadas à função esfingomielinase. Os estudos da Hlb in vitro e in vivo indicam a importância desta toxina na patogenia dos processos infeciosos e como um problema potencial para a saúde pública (Cifrian et al., 1996; Katayama et al., 2013).

Em um experimento in vitro observou-se que a Hlb lesionou as células do epitélio secretor bovino, incrementou o efeito nocivo da $\alpha$ toxina e aumentou a aderência de $S$. aureus às células do epitélio secretor, o que permitiu uma maior proliferação da bactéria (Cifrian et al., 1996). A lise de monócitos humanos pela Hlb apresentou uma cinética rápida, com lise de $50 \%$ dos monócitos $\left(10^{6}\right.$ células $\left./ \mathrm{mL}\right)$ em $60 \mathrm{~min}$. por apenas $0,001 \mathrm{U} / \mathrm{mL}$ de Hlb com liberação no meio de interleucina-1 $\beta$, receptor solúvel de interleucina-6 e CD14 solúvel. Neste sentido, a destruição dos monócitos pela Hlb esteve associada à liberação de citocinas que são importantes no início e na progressão de doenças infecciosas (Walev et al., 1996). Por outro lado, Tajima et al. (2009) observaram o efeito anti-inflamatório in vitro da beta toxina, reduzindo a produção de interleucina 8 mediante a atividade citotóxica das células endoteliais. Huseby et al. (2010) relataram que a Hlb é uma esfingomielinase neutra que forma ligações covalentes entre $S$. aureus na presença de DNA, sendo denominada atividade de ligação de biofilme, independente da atividade da esfingomielinase, sendo a $\beta$ toxina uma potente estimuladora da formação de biofilme.

\section{Toxina $\gamma$ hemolítica ou gama toxina (HIg)}

$\mathrm{O}$ fragmento de $\mathrm{ADN}$ que possui a gama toxina foi clonado em 1988, e a partir das evidências genéticas constatou-se que para a atividade hemolítica acontecer é necessária a ação conjunta de dois polipeptídios codificados por dois genes independentes, sendo os polipeptídeos produzidos de $32 \mathrm{kDa}$ e $36 \mathrm{kDa}$, respectivamente (Cooney et al., 1988). A partir de estudos realizados por Prevost et al. (1995) obteve-se um maior entendimento sobre as propriedades físicoquímicas e biológicas desta toxina e das interrelações entre os polipeptídeos que a compõe. Os polipeptídeos são denominados componentes $\mathrm{S}$ e $\mathrm{F}$ (Slow- and Fast-eluting Proteins). Em isolados que produzem ambos polipeptídeos podem estar presentes uma das três unidades $\mathrm{S}$ ( $\mathrm{HlgA}, \mathrm{HlgC}$ e LukS-PV) e uma das duas unidades F (HlgB e LukF-PV), existindo seis possíveis formas da toxina $\gamma$ hemolítica. Também foi observado uma 
alta porcentagem de sequências idênticas entre as unidades dentro de cada grupo.

Os genes lukS-PV e lukF-PV (PantonValenine-Leukocidin) foram clonados e sequenciados por Prevost et al. (1995). O gene lukS-PV codifica um polipeptídeo de 312 aminoácidos que inclui os 28 aminoácidos residuais que são clivados para obter a forma ativa do polipeptídeo. Já o gene $l u k F-P V$ codifica para 325 aminoácidos, incluindo os 24 aminoácidos residuais que são clivados para obter a forma ativa do polipeptídeo.

Entre as seis possíveis formas da toxina $\gamma$ hemolítica observou-se que as combinações HlgA$\mathrm{HlgB}$, HlgA-LukF-PV e HlgC-HlgB apresentaram alta atividade hemolítica, sendo a $\mathrm{HlgA}-\mathrm{HlgB}$ a que apresentou a maior atividade. As combinações restantes demonstraram baixa atividade hemolítica, no entanto, as seis combinações foram eficientes na lise de leucócitos (König e Prevost, 1997). O efeito clínico e biológico das diferentes combinações da toxina $\gamma$ hemolítica foi avaliado em um modelo in vivo, observando-se a seguinte ordem das diferentes combinações em relação à intensidade da inflamação e necrose: HlgA-LukF-PV > HlgA$\mathrm{HlgB} \geq$ LukS-PV-HlgB $\geq$ LukS-PV-LukF-PV > HlgC-HlgB $\geq$ HlgC-LukF-PV (Siqueira et al., 1997).

\section{Toxina $\delta$ hemolítica ou delta toxina (HId)}

A delta toxina é uma exotoxina de baixo peso molecular (26 aminoácidos) que forma estruturas poliméricas com capacidade de lisar uma ampla diversidade de células. Esta toxina é codificada pelo gene que sintetiza simultaneamente o ARN III que funciona como um regulador global da superfície celular e dos fatores de virulência secretados (Novick, 2003).

O gene hld é formado por 514 nucleotídeos onde os primeiros 160 formam 45 códons de leitura aberta. A delta toxina é produzida por $97 \%$ dos isolados de $S$. aureus e calcula-se que entre 50 a $70 \%$ dos Staphylococcus Coagulase Negativos produzam esta toxina (Dinges et al., 2000).

O mecanismo de ação da delta toxina tem sido objeto de interesse de diferentes estudos. A partir da estrutura secundária de $\alpha$-hélice desta toxina, com presença de domínios hidrofóbicos e hidrofílicos em posições opostas foi proposto que a delta toxina atua como agente surfactante, destruindo a membrana celular. A velocidade com que a célula alvo é lisada suporta esta hipótese, onde primeiro são liberadas partículas de baixo peso molecular com a subsequente exposição à toxina, sendo liberadas moléculas de maior tamanho (Freer e Birkbeck, 1982; Lee et al., 1987).

\section{Enterotoxinas estafilocócica}

As SEs são proteínas pequenas, secretadas no meio, são solúveis em água e solução salina. Os aminoácidos lisina, ácido aspártico, ácido glutâmico e tripsina são abundantes na estrutura primária destas enterotoxinas (Le Loir et al., 2003). Até o momento são conhecidos 23 sorotipos entre enterotoxinas e enterotoxinas-like (Enterotoxinlike SEl) (Wilson et al., 2011; Rall et al., 2014; Ono et al., 2015).

As SEs constituem uma grande família de toxinas que apresentam uma estreita relação filogenética, estruturas comuns, funções e sequências homólogas. Análises cristalográficas revelaram que estas moléculas possuem forma elipsoidal e que são pregueadas de modo a formar dois domínios contendo uma mistura de estruturas $\alpha$-hélices e folhas- $\beta$ pregueadas (Balaban e Rasooly, 2000). As SEs apresentam duas funções, como toxina gastrointestinal e superantígeno que estimula a proliferação de células T não específicas (Jarraud et al., 2001). Estas funções encontram-se localizadas em domínios separados das proteínas, mas correlacionadas, por isto a perda de uma das funções (que pode ser causada por mutações) também determina a perda da outra função (Harris et al., 1993).

A enterotoxigenicidade e o efeito emético estão relacionados à estimulação do sistema nervoso central, após atuação da toxina nos receptores neurais dos intestinos (Monday e Bohach, 1999). As intoxicações alimentares por SEs são caracterizadas por apresentar um curto período de incubação ( 2 a 6 horas) após ingestão da toxina, seguido por náusea, vômito, dor abdominal e diarreia. Na maioria dos hospedeiros, a diarreia ocorre devido ao aumento do peristaltismo intestinal e perda de líquido pelo organismo (Balaban e Rasooly, 2000). Também foi sugerido por $\mathrm{Hu}$ et al. (2005) que o contato desta enterotoxina com o epitélio intestinal compromete a função epitelial pelo aumento da liberação de cálcio intracelular, e seu efeito sobre a sinalização celular deste tecido. As SEs são resistentes à atividade das proteases gastrointestinais como por exemplo a pepsina e tripsina (Cretenet et al., 2011) e mantém suas atividades biológicas mesmo após serem submetidas a altas temperaturas (Senger e Bizani, 2011). 
A atividade como superantígeno implica na proliferação de células $\mathrm{T}$ não específicas. Para desencadear a resposta imune celular mediada por células $\mathrm{T}$, o primeiro evento é o reconhecimento do antígeno pelo receptor de membrana das células $\mathrm{T}$ ( $T$ Cell Antigen Receptor TCR) (Fields et al., 1996). O antígeno é apresentado pelo TCR na forma de peptídeo processado associado com moléculas do complexo maior de histocompatibilidade (Major Histocompatibility Complex MHC) classe I e II, que são proteínas de membrana exibidas na superfície de células apresentadoras de antígeno (Fink et al., 1986). Este tipo de reconhecimento é a base para a alta especificidade da resposta imune onde poucas células $\mathrm{T}$ podem reconhecer um antígeno específico.

Por outro lado, a atividade como superantígeno das SEs permite interatuar com muitas células $\mathrm{T}$ de forma inespecífica, sendo um forte ativador de linfócitos T (Le Loir et al., 2003). Os receptores (TCR V $\beta$ ) para as SEs nas células apresentadoras de antígeno interagem com a molécula MHC da classe II, promovendo a ativação de forma inespecífica das células $\mathrm{T}$ (Choi et al., 1989/1990). Devido a essa interação, as SEs ativam até $25 \%$ dos linfócitos T (Kappler et al., 1994); em contraste, os antígenos clássicos estimulam 0,0001-0,01\% das células T (Fink et al., 1986). A ativação de forma inespecífica das células $\mathrm{T}$ junto a segregação massiva de citocinas, como por exemplo fator de necrose tumoral (TNF) $\alpha$ e $\beta$, interleucinas (IL) 1 e 2 e interferon (INF) $\gamma$ é responsável pelos sinais clínicos observados na septicemia e na síndrome do choque tóxico, levando as células à apoptose e resultando em imunossupressão (Rellahan et al., 1990).

\section{Enterotoxina estafilocócica A (SEA)}

O gene que codifica para SEA (sea) é carreado por um fago ( $\Phi$ Sa3) (Betley e Mekalanos, 1985). Estudos de hibridação do DNA sugerem que este fago se integra ao cromossomo bacteriano por circularização e cruzamento recíproco. O gene é composto por 771 nucleotídeos que codificam o precursor da enterotoxina A que apresenta 257 resíduos de aminoácidos (Huang et al., 1987). A forma ativa da SEA é obtida após a remoção de 24 aminoácidos na porção hidrofóbica final da sequência (Betley e Mekalanos, 1988). Existem três isoformas com diferentes pontos isoelétricos que sugerem variações no processamento ou modificações pós-tradução. A expressão da SEA começa desde a segunda metade da fase de crescimento exponencial não sendo regulada pelo gene acessório regulador (agr) (Tremaine et al., 1993).

\section{Enterotoxina estafilocócica B (SEB)}

$O$ gene seb pode ser encontrado no cromossomo bacteriano (Shafer e Iandolo, 1978), em um plasmídeo de $0,75 \times 10^{6} \mathrm{Da}$ (Shalita et al., 1977) e no plasmídeo pZA10 de 56,2 kilo-bases (Altboum et al., 1985). O gene possui aproximadamente 801 nucleotídeos (Johns e Khan, 1988), e a proteína precursora da enterotoxina B está formada por 267 aminoácidos, incluindo 27 resíduos de aminoácidos na porção final da sequência que é removido para a obtenção da SEB funcional. O gene seb é observado no cromossomo bacteriano em estirpes de $S$. aureus isoladas de casos clínicos de intoxicação alimentar (Shafer e Iandolo, 1978). Contudo, em outras estirpes de S. aureus, o gene seb é carreado por um plasmídeo de 750kb (Shalita et al., 1977).

\section{Enterotoxina estafilocócica C (SEC)}

As SECs são formadas por um grupo de enterotoxinas (SEC1, SEC2 e SEC3) conservadas com significativa relação imunológica cruzada (Bergdoll et al., 1965). Em isolados obtidos de bovinos observou-se que o gene sec é transportado pela ilha de patogenicidade SaPIbov (Fitzgerald et al., 2001). O gene secl é transportado pelo plasmídeo pZA10 de 56,2 kilo-bases (Altboum et al., 1985). Os genes $\sec 1$, sec 2 e $\sec 3$ apresentam 801 nucleotídeos e codificam proteínas precursoras das enterotoxinas de 266 aminoácidos contendo 27 resíduos de aminoácidos que são removidos para obter as enterotoxinas na sua forma ativa extracelular (Couch e Betley, 1989). A SEC3 difere da SEC2 em quatro aminoácidos e da SEC1 em nove aminoácidos; os 167 resíduos de aminoácidos terminais são idênticos nos três tipos de enterotoxinas com exceção de um aminoácido conservado no SEC3 (Hovde et al., 1990). Analisando isolados de $S$. aureus obtidos de bovinos e ovinos Marr et al. (1993) observaram que cada estirpe produzia uma variante específica para cada hospedeiro; este resultado sugere que a heterogeneidade da toxina se deve a um processo de modificação e seleção do gene $\sec$ que facilite a sobrevivência do $S$. aureus no respectivo hospedeiro. 


\section{Enterotoxina estafilocócica D (SED)}

O gene sed está localizado no plasmídeo penicilinase de 27,6 kilo-bases denominado pIB485, estando este plasmídeo presente em todas os isolados de $S$. aureus produtores de SED. O gene sed contém 777 nucleotídeos e codifica a proteína precursora de 258 aminoácidos que contém 30 resíduos de aminoácidos que serão removidos para obter a enterotoxina na sua forma ativa (Bayles e Iandolo, 1989). Esta enterotoxina é parte do grupo dos superantígenos (SEA, SED, SEE, SEH, SEI e SEJ) dependente de zinco para aumentar a afinidade na interação com a molécula do MHC classe II (Petersson et al., 2001). A síntese da SED é regulada mediante o gene acessório regulador (agr) de $S$. aureus. Como resultado dessa regulação, a expressão do sed acontece após a fase exponencial de crescimento (Bayles e Iandolo, 1989).

\section{Enterotoxina estafilocócica E (SEE)}

$\mathrm{O}$ gene see localiza-se em bacteriófago e apresenta $84 \%$ da sequência de nucleotídeos homóloga com a do gene sea. O gene see contém 774 nucleotídeos sendo a SEE sintetizada como uma proteína precursora de 257 aminoácidos e a forma ativa da enterotoxina contém 230 resíduos de aminoácidos (Couch et al., 1988).

\section{Enterotoxina estafilocócica G (SEG)}

Os genes seg e sei foram descritos inicialmente em duas estirpes de $S$. aureus (Munson et al., 1998), mas ambos os genes coexistiram nos isolados clínicos de $S$. aureus avaliados por Jarraud et al., (1999). O gene seg encontra-se no agrupamento de genes de enterotoxinas no cromossomo bacteriano (Enterotoxin Gene Closter egc) (Jarraud et al., 2001). Este gene contém 777 nucleotídeos e codifica uma proteína precursora de 258 aminoácidos que é clivada para obter-se a enterotoxina ativa com 233 aminoácidos (Munson et al., 1998).

\section{Enterotoxina estafilocócica H (SEH)}

O gene seh descrito por Ren et al. (1994) possui 654 nucleotídeos em sua sequência de DNA e codifica a proteína ativa de 218 aminoácidos. A sequência de aminoácidos terminal $\mathrm{NH}_{2}$ é única e nos testes imunológicos não foi identificada atividade cruzada entre a SEH e as enterotoxinas previamente descritas (Su e Wong, 1995).

\section{Enterotoxina estafilocócica I (SEI)}

$\mathrm{O}$ gene sei também é localizado no agrupamento de genes de enterotoxinas no cromossomo bacteriano (Jarraud et al., 2001). É formado por 729 nucleotídeos e sintetiza o precursor de 242 aminoácidos; a enterotoxina na sua forma ativa é composta por 218 aminoácidos (Munson et al., 1998).

\section{Enterotoxina estafilocócica J (SEJ)}

O plasmídeo penicilinase de 27,6 kilo-bases (pIB485) revelou um enquadramento de leitura aberta que codifica a SEJ. Os genes sed e $s e j$ transcrevem-se em direções opostas e estão separados por 895 nucleotídeos. Os estudos de amplificação por PCR do gene sej sugerem que os isolados de $S$. aureus portadores do plasmídeo com o gene sed também apresentam o gene sej (Zhang et al., 1998).

No espaço entre os genes seg e sei e as regiões que limitam o agrupamento de genes de enterotoxinas observam-se três regiões de leitura aberta referentes às enterotoxinas-like designadas sek, sel e sem e também dois pseudogenes $\psi$ entl e $\psi$ ent2 (Jarraud et al., 2001).

\section{Toxina da síndrome do choque tóxicoTSST-1 (Toxic Shock Syndrome Toxin-1)}

Inicialmente, a TSST-1 foi classificada como SEF, o que explica que na atualidade não exista esse sorotipo. O gene tst é transportado pela ilha de patogenicidade SaPIbov (Fitzgerald et al., 2001). Este gene é significativamente mais frequente em isolados de $S$. aureus associados às doenças em animais quando comparados aos isolados de humanos (Van Leeuwen et al., 2005). As SEs e as TSST-1 apresentam estrutura e atividade biológica comuns (toxina gastrointestinal e superantígeno), o que sugere que derivam de um ancestral comum. Apresentam significativa homologia na estrutura primária, secundária e terciária (Marrack e Kappler, 1990). A toxina do choque tóxico determina manifestações clínicas como febre acima de $39^{\circ} \mathrm{C}$, exantema com descamação, hipotensão, podendo afetar os sistemas muscular (mialgia severa), renal (elevação de uréia e creatinina), hepático (elevação das transaminases e hiperbilirubinemia), hematopoetico (trombocitopenia e linfocitopenia) e nervoso central (desorientação, sem sinais neurológicos focais) (Veronesi e Focaccia, 1997). 


\section{Polissacarídeo capsular}

A maioria dos isolados de $S$. aureus envolvidos em infeções tanto nos humanos como em animais produzem polissacarídeo capsular (Capsular Polysaccharide CP), sendo os sorotipos 5 (CP5) e 8 (CP8), os mais frequentes (O'Riordan e Lee, 2004). Outros dois sorotipos descritos foram os CP1 e CP2, baseados nas reações com antissoros de coelho (Karakawa e VAnn, 1982). Os isolados com estes sorotipos produzem colônias mucóides em meio sólido e são raramente encontradas nos isolados clínicos (Arbeit et al., 1984; Sompolinsky et al., 1985). Os isolados que não reagem com os antissoros CP1, 2, 5 e 8 devem ser denominados como não tipificáveis (O'Riordan e Lee, 2004).

A expressão dos sorotipos CP5 e CP8 é influenciada por condições ambientais e de crescimento da bactéria. Por exemplo, o crescimento de $S$. aureus em meio de cultura com limitações de ferro e sódio favorece a expressão CP8 (Lee et al., 1993). A expressão do CP5 pode ser comprometida por altas concentrações de extrato de levedura, condições de crescimento alcalinas (Dassy et al., 1991), incremento nas concentrações de $\mathrm{CO}_{2}$ (Stringfellow et al., 1991; Herbert et al., 1997) e anaerobiose (Dassy et al., 1991); porém a expressão do CP5 é favorecida quando o crescimento acontece no leite (Sutra et al., 1990).

Em relação à função do polissacarídeo capsular, a teoria mais aceita é de que a patogênese das infeções estafilocócicas confere proteção antifagocitária o que permite a persistência do micro-organismo no sangue ou em tecidos do hospedeiro (Sutra et al., 1990; Thakker et al., 1998). Outros grupos de pesquisadores acreditam que a não expressão do polissacarídeo capsular permite que esses isolados persistam por maior tempo no nicho intracelular da glândula mamária, enquanto que os isolados que expressam os polissacarídeos capsulares promovem maior reação inflamatória e são eliminados mais rapidamente (Tuchscherr et al., 2005). Estudos recentes sugerem que isolados com genótipos cap5-agr grupo I estão melhores adaptados às condições ambientais hostis que os genótipos cap8agr grupo II, além de que este último genótipo (cap8-agr II) apresenta menor capacidade invasiva (Bardiau et al., 2016).

As estruturas bioquímicas dos polissacarídeos capsular CP1 (Murthy et al., 1983), CP2 (Hanessian e Haskell, 1964), CP5 (Moreau et al., 1990) e CP8 (Fournier et al., 1984) podem ser observadas na Figura 2. O CP5 e CP8 apresentam açúcares similares repetidos, mas os dois polissacarídeos são sorologicamente distintos devido às diferenças nas uniões entre os açúcares e o sítio de O-acetilação do monossacarídeo residual (Jones, 2005).

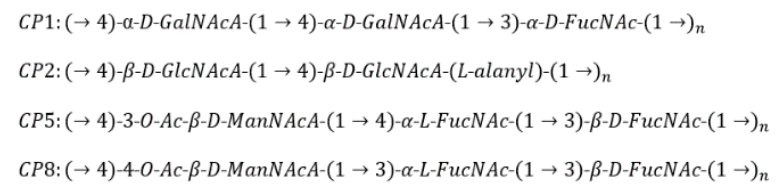

Figura 2. Estruturas bioquímicas dos polissacarídeos capsulares.

Os genes que codificam para CP5 e CP8 são cromossômicos e de natureza alélica. O cluster de genes capsular está formado por 16 genes intimamente ligados, desde o cap5(8) A até cap5(8) $\mathrm{P}$ transcritos em um único sentido. As regiões centrais cap5(8) HIJK são homólogas entre si e específica para o alelo (Figura 3) (Cocchiaro et al., 2006). Neste sentido, destaca-se que alguns estudos descrevem isolados portadores de ambos os genes, quando isso biologicamente não poderia ser possível, sendo mais provável o isolamento de duas estirpes diferentes cada uma portadora de um dos alelos. Por exemplo, no trabalho publicado por Kumar et al. (2011) um dos isolados obtidos de casos de mastites clínica seria hipoteticamente portador dos dois alelos ou do trabalho publicado por Ote et al. (2011) em que 5/229 isolados de $S$. aureus causadores de mastite em bovinos apresentariam iguais características. Salasia et al. (2011) ressaltam o grande número de isolados que são descritos como portadores dos dois alelos cap5(8), sendo 39,02\% (16/41) do total dos isolados avaliados. Mais recentemente o trabalho publicado por Waryah et al. (2014) descreve um isolado como portador dos dois alelos.

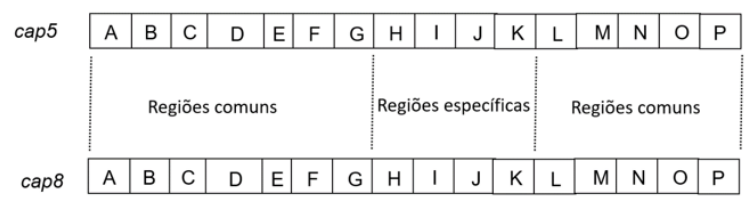

Figura 3. Diagrama esquemático das diferentes regiões dos loci cap5 e cap8 (Cocchiaro et al., 2006). Cada quadrado representa os genes individuais formadores de cada locus.

\section{Formação de biofilme}

Os biofilmes são comunidades estruturadas de células bacterianas encapsuladas em uma matriz de polímeros auto-produzidos e aderidos a uma 
superfície viva ou inerte (Costerton et al., 1999). O modelo de crescimento bacteriano em biofilme explica a ineficácia dos anticorpos (Lam et al., 1987) e células brancas (Leid et al., 2005) frente a estas comunidades bacterianas. Stewart (2002) demonstrou a ineficácia de antimicrobianos frente às bactérias com crescimento em biofilme. Também foi observado que o biofilme tem a capacidade de induzir hiper-inflamação no hospedeiro favorecendo altos níveis de citocinas pró-inflamatórias (Trengove et al., 1996) e grande número de neutrófilos (Diegelmann, 2003).

A formação de biofilme é um dos mais importantes mecanismos de sobrevivência da bactéria no nicho extracelular. Confere proteção frente ao sistema imune do hospedeiro e atividade aos agentes antimicrobianos (Jolivet-Gougeon e Bonnaure-Mallet, 2014). A proteção frente ao sistema imune do hospedeiro é conferida pelo polímero formador do biofilme frente à atividade fagocitária dos macrófagos, opsonização e frente às espécies reativas de oxigênios dos polimorfonucleares (Johnson et al., 1986; Yasuda et al., 1994). Também foi observada uma diminuição da atividade bactericida dos neutrófilos frente a isolados de $S$. aureus produtores de biofilme (Barrio et al., 2000). Diferentes mecanismos são conhecidos como responsáveis pela resistência de micro-organismos com crescimento em biofilme frente a agentes antimicrobianos podendo ser mencionados: diminuição da penetração do agente antimicrobiano dentro do biofilme, alteração da taxa de crescimento dos micro-organismos dentro do biofilme e modificações fisiológicas nas bactérias devido ao modo de crescimento no biofilme, incluindo as células persistentes (Melchior et al., 2006).

A fase planctônica de crescimento microbiano pode ser vista como a fase de dispersão do agente de uma superfície a outra. Na maioria dos ambientes naturais, os micro-organismos tentam se aderir às superfícies disponíveis. Após a aderência inicial da bactéria na superfície, a motilidade superficial e a divisão binária são responsáveis pela incorporação de células aderidas (Stoodley et al., 2002). A fase inicial de formação de biofilme inclui duas sub-etapas: a primeira compreende a adesão das células a uma superfície, facilitada por adesinas associadas à parede celular que é resultado da interação de diferentes genes (Mack, 1999). A segunda sub-etapa é caracterizada pela multiplicação celular e formação da estrutura madura de biofilme consistente em muitas camadas de células conectadas entre si por um polissacarídeo extracelular (Yarwood e Schlievert, 2003). Finalmente no processo de maturação, muitos Staphylococcus geram uma camada viscosa que oferece maior proteção às bactérias no biofilme. A natureza química dessa camada viscosa ainda não foi bem definida, mas evidências sugerem que esta é formada predominantemente por polissacarídeos hidratados (Melchior et al., 2006).

O potencial de crescimento do biofilme bacteriano é limitado pela disponibilidade de nutrientes dentro do biofilme e os diferentes canais de fluxo através do biofilme visam manter a perfusão de nutrientes (Stoodley et al., 2002). Outros fatores que influenciam a maturação do biofilme são o pH interno, a perfusão de oxigênio, a fonte de carbono e a osmolaridade. Quando o biofilme atinge uma massa crítica, a camada de células externas começa a gerar células no estado planctônico, as quais ficam livres do biofilme e colonizam outras superfícies (Dunne, 2002).

A capacidade de formar biofilme pelos Staphylococcus pode ser estudada pela expressão fenotípica do biofilme ou pela triagem dos genes associados com esta formação. Estudo conduzido por Oliveira et al. (2006) indicou que isolados de $S$. aureus e $S$. epidermidis obtidos de amostras de leite bovino com mastites subclínica são produtores de biofilme. Outro estudo conduzido na Argentina revelou altas frequências na expressão fenotípica do biofilme, assim como de genes que favorecem a adesão e formação de biofilme nos isolados de S. aureus e Staphylococcus coagulase-negativos (SCN) causadores de mastites em bovinos (Felipe et al., 2017). No caso do S. aureus, a produção de biofilme diminui significativamente nos casos de mastites, mas aumenta a capacidade de colonização da glândula mamária (Cucarella et al., 2004).

A produção de biofilme está associada aos loci ica (Intercellular Adhesion), bap (BiofilmAssociated Protein), agr (Accessory Gene Regulator) e sar (Staphylococcal Accessory Regulator). Porém, os isolados com capacidade de produzir biofilme não necessariamente portam todos estes genes, o que demonstra que outros mecanismos também estão relacionados à formação de biofilme (Fox et al., 2005; Lasa e Penadés, 2006; Planchon et al., 2006).

No estudo de Tormo et al. (2005) foi identificado, clonado e sequenciado o gene bap em diferentes espécies de SCN (S. epidermidis, $S$. 
chromogenes, S. xylosus, S. simulans e S. hyicus). Os autores observaram uma alta similaridade deste gene quando comparado com o gene ortólogo de $S$. aureus, o que sugere uma transferência genética horizontal da ilha de patogenicidade SaPIbov2; os isolados portadores do gene bap foram fortes produtores de biofilmes e não foram detectados os operons icaABCD em nenhum deles.

No crescimento bacteriano em biofilme, a detecção de quórum constitui um mecanismo de comunicação célula a célula que permite a sincronia na expressão de genes em resposta à densidade na população celular (Solano et al., 2014). No caso de $S$. aureus, a regulação da detecção de quórum no desenvolvimento do biofilme é dependente do sistema agr (Vuong et al., 2000; Boles e Horswill, 2008). No estudo de Solano et al. (2014) é salientado que moléculas surfactantes similares em diferentes espécies bacterianas são capazes de induzir a dispersão do biofilme; neste sentido a utilização simultânea de moléculas surfactantes com antimicrobianos poderia ser uma alternativa promissora para a erradicação de biofilmes bacterianos. Na revisão de Blackledge et al. (2013) é compilada informação referente a pequenas moléculas que interferem com a comunicação bacteriana e vias de sinalização que dificultam a detecção de quórum e dois componentes do sistema de tradução de sinais. Também é abordada a utilização de enzimas que degradam componentes da matriz extracelular provocando a destruição do mesmo (Blackledge et al., 2013). Outras estratégias para combater a formação de biofilme bacteriano são a inibição da adesão bacteriana no primeiro estágio de formação do biofilme (inibição não específica e específica da adesão) e estratégias que visam aumentar a tolerância de biofilme aos antibióticos para aumentar o tempo de ação dos mesmos (Beloin et al., 2014).

\section{Considerações Finais}

Os estudos dos processos infeciosos com a participação de $S$. aureus requerem a compreensão dos mecanismos de adesão bacterianas, toxicidade celular e evasão deste patógeno, além do conhecimento dos mecanismos de defesa do hospedeiro, que são abordados frequentemente em pesquisas. $\mathrm{O}$ aprofundamento nos estudos dos diferentes mecanismos de ação dos fatores de virulência permitirá vislumbrar novas estratégias para interferir nas atividades de toxinas ou família de proteínas associadas a fatores de virulência.

\section{Agradecimentos}

À FACEPE (Processo IBP-0439-5.05/12) e ao $\mathrm{CNPq}$ (Processo 442746/2014-8) por propiciar a manutenção das pesquisas nesta área.

\section{Referências}

Aarestrup, F.M.; Larsen, H.; Eriksen, N.; Elsberg, C.; Jensen, N. Frequency of $\alpha$-and $\beta$ haemolysin in Staphylococcus aureus of bovine and human origin. Acta Pathologica, Microbiologica, et Immunologica Scandinavica, 107(1-6): 425-430, 1999.

Adhikari, R.P.; Ajao, A.O.; Aman, M.J.; Karauzum, H.; Sarwar, J.; Lydecker, A.D.; Johnson, J.K.; Nguyen, C.; Chen, W.H.; Roghmann, M.-C. Lower antibody levels to Staphylococcus aureus exotoxins are associated with sepsis in hospitalized adults with invasive $S$ aureus infections. The Journal of Infectious Diseases, 206(6): 915923, 2012.

Al-Dabbagh, M.; Dobson S. Infectious hazards from pets and domestic animals. In: Curtis, N.;

Finn, A.; Pollard, A.J. Hot topics in infection and immunity in children VII. Springer New York, 2011, p.261-272.

Altboum, Z.; Hertman, I.; Sarid, S. Penicillinase plasmid-linked genetic determinants for enterotoxins $\mathrm{B}$ and $\mathrm{C} 1$ production in Staphylococcus aureus. Infection and Immunity, 47(2): 514-521, 1985.

Arbeit, R.D.; Karakawa, W.W.; Vann, W.F.; Robbins, J.B. Predominance of two newly described capsular polysaccharide types among clinical isolates of Staphylococcus aureus. Diagnostic Microbiology and Infectious Disease, 2(2): 85-91, 1984.

Balaban, N.; Rasooly, A. Staphylococcal enterotoxins. International Journal of Food Microbiology, 61(1): 1-10, 2000.

Bardiau, M.; Caplin, J.; Detilleux, J.; Graber, H.; Moroni, P.; Taminiau, B.; Mainil, J.G. Existence of two groups of Staphylococcus aureus strains isolated from bovine mastitis based on biofilm formation, intracellular survival, capsular profile and agr-typing. Veterinary Microbiology, 185: 1-6, 2016.

Barrio, B.; Vangroenweghe, F.; Dosogne, H.; Burvenich, C. Decreased neutrophil bactericidal activity during phagocytosis of a slime-producing Staphylococcus aureus strain. Veterinary Research, 31(6): 603-609, 2000 . 
Bayles, K.W.; Iandolo, J.J. Genetic and molecular analyses of the gene encoding staphylococcal enterotoxin D. Journal of Bacteriology, 171(9): 4799-4806, 1989.

Beloin, C.; Renard, S.; Ghigo, J.M.; Lebeaux, D. Novel approaches to combat bacterial biofilms. Current Opinion in Pharmacology, 18: 61-68, 2014.

Bergdoll, M.S.; Borja, C.R.; Avena, R.M. Identification of a new enterotoxin as enterotoxin C. Journal of Bacteriology, 90(5): 1481-1485, 1965.

Bernheimer, A.W.; Avigad, L.S.; Kim, K.S. Staphylococcal sphingomyelinase $(\beta-$ hemolysin). Annals of the New York Academy of Sciences, 236(1): 292-306, 1974.

Berube, B.J.; Wardenburg, J.B. Staphylococcus aureus $\alpha$-toxin: Nearly a century of intrigue. Toxins, 5(6): 1140-1166, 2013.

Betley, M.; Mekalanos, J. Nucleotide sequence of the type A staphylococcal enterotoxin gene. Journal of Bacteriology, 170(1): 34-41, 1988.

Betley, M.J.; Mekalanos, J.J. Staphylococcal enterotoxin A is encoded by phage. Science, 229(4709): 185-187, 1985.

Blackledge, M.S.; Worthington R.J.; Melander C. Biologically inspired strategies for combating bacterial biofilms. Current Opinion in Pharmacology, 13(5): 699-706, 2013.

Boles, B. R.; Horswill, A.R. Agr-mediated dispersal of Staphylococcus aureus biofilms. PLoS Pathogens, 4(4): e1000052, 2008.

Carfora, V.; Caprioli, A.; Marri, N.; Sagrafoli, D.; Boselli, C.; Giacinti, G.; Giangolini, G.; Sorbara, L.; Dottarelli, S.; Battisti, A.; Amatiste, S. Enterotoxin genes, enterotoxin production, and methicillin resistance in Staphylococcus aureus isolated from milk and dairy products in Central Italy. International Dairy Journal, 42: 12-15, 2015.

Cassidy, P.; Harshman, S. Studies on the binding of staphylococcal 125I-labeled $\alpha$-toxin to rabbit erythrocytes. Biochemistry, 15(11): 2348-2355, 1976.

Cassidy, P.S.; Harshman, S. The binding of staphylococcal ${ }^{125}$ I- $\alpha$-toxin (b) to erythrocytes. The Journal of Biological Chemistry, 248(15): 5545-5546, 1973.

Chavakis, T.; Preissner, K.T.; Herrmann, M. The anti-inflammatory activities of Staphylococcus aureus. Trends in Immunology, 28(9): 408-418, 2007.
Choi, Y.-W.; Kotzin, B.; Herron, L.; Callahan, J.; Marrack, P.; Kappler, J. Interaction of Staphylococcus aureus toxin" superantigens" with human $\mathrm{T}$ cells. Proceedings of the National Academy of Sciences, 86(22): 8941-8945, 1989.

Choi, Y.; Herman, A.; DiGiusto, D.; Wade, T.; Marrack, P.; Kappler, J. Residues of the variable region of the T-cell-receptor $\beta$-chain that interact with $S$. aureus toxin superantigens. Nature, 346: 471-473, 1990.

Cifrian, E.; Guidry, A.J.; Bramley, A.J.; Norcross, N.L.; Bastida-Corcuera, F.D.; Marquardt, W.W. Effect of staphylococcal $\beta$ toxin on the cytotoxicity, proliferation and adherence of Staphylococcus aureus to bovine mammary epithelial cells. Veterinary Microbiology, 48(3): 187-198, 1996.

Clarke, S.R.; Foster S.J. Surface adhesins of Staphylococcus aureus. Advances in Microbial Physiology, 51: 187-224, 2006.

Cocchiaro, J.L.; Gomez, M.I.; Risley, A.; Solinga, R.; Sordelli, D. O.; Lee, J. C. Molecular characterization of the capsule locus from non-typeable Staphylococcus aureus. Molecular Microbiology, 59(3): 948-960, 2006.

Cooney, J.; Mulvey, M.; Arbuthnott, J. P.; Foster, T.J. Molecular cloning and genetic analysis of the determinant for gamma-lysin, a twocomponent toxin of Staphylococcus aureus. Journal of General Microbiology, 134(8): 2179-2188, 1988.

Costerton, J. Overview of microbial biofilms. Journal of Industrial Microbiology, 15(3): 137-140, 1995.

Costerton, J.W.; Stewart, P. S.; Greenberg, E.P. Bacterial biofilms: a common cause of persistent infections. Science, 284(5418): 1318-1322, 1999.

Couch, J.L.; Betley, M.J. Nucleotide sequence of the type C3 staphylococcal enterotoxin gene suggests that intergenic recombination causes antigenic variation. Journal of Bacteriology, 171(8): 4507-4510, 1989

Couch, J.L.; Soltis, M.T.; Betley, M.J. Cloning and nucleotide sequence of the type $\mathrm{E}$ staphylococcal enterotoxin gene. Journal of Bacteriology, 170(7): 2954-2960, 1988.

Cretenet, M.; Even S.; Le Loir, Y. Unveiling Staphylococcus aureus enterotoxin production in dairy products: a review of recent advances to face new challenges. Dairy 
Science \& Technology, 91(2): 127-150, 2011.

Cucarella, C.; Tormo, M.Á.; Ubeda, C.; Trotonda, M.P.; Monzón, M.; Peris, C.; Amorena, B.; Lasa, Í.; Penadés, J.R. Role of biofilmassociated protein bap in the pathogenesis of bovine Staphylococcus aureus. Infection and Immunity, 72(4): 2177-2185, 2004.

Dassy, B.; Stringfellow, W.; Lieb, M.; Fournier, J. Production of type 5 capsular polysaccharide by Staphylococcus aureus grown in a semisynthetic medium. Journal of General Microbiology, 137(5): 1155-1162, 1991.

DeLeo, F.R.; Kennedy, A.D.; Chen, L.; Wardenburg, J.B.; Kobayashi, S.D.; Mathema, B.; Braughton, K.R.; Whitney, A.R., Villaruz, A. E.; Martens, C. A. Molecular differentiation of historic phagetype $80 / 81$ and contemporary epidemic Staphylococcus aureus. Proceedings of the National Academy of Sciences, 108(44): 18091-18096, 2011.

Diegelmann, R.F. Excessive neutrophils characterize chronic pressure ulcers. Wound Repair and Regeneration, 11(6): 490-495, 2003.

Dinges, M.M.; Orwin P.M.; Schlievert, P.M. Exotoxins of Staphylococcus aureus. Clinical Microbiology Reviews, 13(1): 16-34, 2000.

Dunne, W.M. Bacterial adhesion: seen any good biofilms lately? Clinical Microbiology Reviews, 15(2): 155-166, 2002.

Fairweather, N.; Kennedy, S.; Foster, T.; Kehoe, M.; Dougan, G. Expression of a cloned Staphylococcus aureus alpha-hemolysin determinant in Bacillus subtilis and Staphylococcus aureus. Infection and Immunity, 41(3): 1112-1117, 1983.

Felipe, V.; Morgante, C.A.; Somale, P.S.; Varroni, F.; Zingaretti, M.L.; Bachetti, R.A.; Correa, S.G.; Porporatto, C. Evaluation of the biofilm forming ability and its associated genes in Staphylococcus species isolates from bovine mastitis in Argentinean dairy farms. Microbial Pathogenesis, 104: 278-286, 2017.

Fields, B.A.; Malchiodi, E.L.; Li, H.; Ysern, X.; Stauffacher, C.V.; Schlievert P.M.; Karjalainen K.; Mariuzza, R.A. Crystal structure of a T-cell receptor $\beta$-chain complexed with a superantigen. Nature, 384(14): 118-192, 1996.

Fink, P.J.; Matis, L.A.; McElligott, D.L.; Bookman, M.; Hedrick, S.M. Correlations between T-cell specificity and the structure of the antigen receptor. Nature, 321(6067): 219226, 1986.

Fitzgerald, J.R.; Monday, S.R.; Foster, T.J.; Bohach, G.A.; Hartigan, P.J.; Meaney, W. J.; Smyth, C.J. Characterization of a putative pathogenicity island from bovine Staphylococcus aureus encoding multiple superantigens. Journal of Bacteriology, 183(1): 63-70, 2001.

Fluit, A. Livestock-associated Staphylococcus aureus. Clinical Microbiology and Infection, 18(8): 735-744, 2012.

Foster, T.J. Immune evasion by staphylococci. Nature Reviews Microbiology, 3(12): 948958, 2005.

Foster, T. J.; Höök, M. Surface protein adhesins of Staphylococcus aureus. Trends in Microbiology, 6(12): 484-488, 1998.

Fournier, J.-M.; Vann, W. F.; Karakawa, W.W. Purification and characterization of Staphylococcus aureus type 8 capsular polysaccharide. Infection and Immunity, 45(1): 87-93, 1984.

Fox, L.K., Zadoks, R.N.; Gaskins, C.T. Biofilm production by Staphylococcus aureus associated with intramammary infection. Veterinary Microbiology, 107(3-4): 295299, 2005.

Freer, J.; Birkbeck, T. Possible conformation of delta-lysin, a membrane-damaging peptide of Staphylococcus aureus. Journal of Theoretical Biology, 94(3): 535-540, 1982.

Fritz, S.A.; Tiemann, K.M.; Hogan, P.G.; Epplin, E.K.; Rodriguez, M.; Al-Zubeidi, D.N.; Wardenburg, J. B.; Hunstad, D.A.A serologic correlate of protective immunity against community-onset Staphylococcus aureus infection. Clinical Infectious Diseases, 56(11): 1554-1561, 2013.

Glenny, A.T.; Stevens, N.F. Staphylococcal toxins and antitoxins. The Journal of Pathology and Bacteriology, 40: 210, 1935.

Gray, G.S.; Kehoe, M. Primary sequence of the alpha-toxin gene from Staphylococcus aureus wood 46. Infection and Immunity, 46(2): 615-618, 1984.

Haim, M.; Trost, A.; Maier, C.; Achatz, G.; Feichtner, S.; Hintner, H.; Bauer, J.; Önder, K. Cytokeratin 8 interacts with clumping factor B: a new possible virulence factor target. Microbiology, 156(12): 3710-3721, 2010. 
Hair, P.S.; Echague, C.G.; Sholl, A.M.; Watkins, J.A.; Geoghegan, J.A.; Foster, T.J.; Cunnion, K.M. Clumping factor A interaction with complement factor I increases C3b cleavage on the bacterial surface of Staphylococcus aureus and decreases complement-mediated phagocytosis. Infection and Immunity, 78(4): 1717-1727, 2010.

Hanessian, S.; Haskell T.H. Structural studies on staphylococcal polysaccharide antigen. The Journal of Biological Chemistry, 239(9): 2758-2764, 1964.

Harris, T.; Grossman, D.; Kappler, J.; Marrack, P.; Rich, R.; Betley, M. Lack of complete correlation between emetic and T-cellstimulatory activities of staphylococcal enterotoxins. Infection and Immunity, 61(8): 3175-3183, 1993.

Hasman, H.; Moodley, A.; Guardabassi, L.; Stegger, M.; Skov, R.; Aarestrup, F.M. spa type distribution in Staphylococcus aureus originating from pigs, cattle and poultry. Veterinary Microbiology, 141(3): 326-331, 2010.

Herbert, S.; Worlitzsch, D.; Dassy, B.; Boutonnier, A.; Fournier, J.-M.; Bellon, G.; Dalhoff, A.; Döring, G. Regulation of Staphylococcus aureus capsularpolysaccharidetype 5: $\mathrm{CO}_{2}$ inhibition in vitro and in vivo. The Journal of Infectious Diseases, 176(2): 431-438, 1997.

Hildebrand, A.; Pohl, M.; Bhakdi, S. Staphylococcus aureus alpha-toxin. Dual mechanism of binding to target cells. The Journal of Biological Chemistry, 266(26): 17195-17200, 1991.

Hovde, C.; Hackett, S.; Bohach, G. Nucleotide sequence of the staphylococcal enterotoxin $\mathrm{C} 3$ gene: sequence comparison of all three type $\mathrm{C}$ staphylococcal enterotoxins. Molecular Genetics and Genomics, 220(2): 329-333, 1990.

Hu, C.; Gong, R.; Guo, A.; Chen, H. Protective effect of ligand-binding domain of fibronectin-binding protein on mastitis induced by Staphylococcus aureus in mice. Vaccine, 28(24): 4038-4044, 2010.

Hu, D.-L.; Suga, S.; Omoe, K.; Abe, Y.; Shinagawa, K.; Wakui, M.; Nakane, A. Staphylococcal enterotoxin A modulates intracellular $\mathrm{Ca}^{2+}$ signal pathway in human intestinal epithelial cells. FEBS Letters, 579(20): 4407-4412, 2005.
Huang, I.; Hughes, J.; Bergdoll, M.; Schantz, E. Complete amino acid sequence of staphylococcal enterotoxin A. The Journal of Biological Chemistry, 262(15): 7006, 1987.

Huseby, M.; Shi, K.; Brown, C.K.; Digre, J.; Mengistu, F.; Seo, K.S.; Bohach, G.A.; Schlievert, P.M.; Ohlendorf, D.H.; Earhart, C.A. Structure and biological activities of beta toxin from Staphylococcus aureus. Journal of Bacteriology, 189(23): 8719-8726, 2007.

Huseby, M.J.; Kruse, A.C.; Digre, J.; Kohler, P.L.; Vocke, J.A., Mann, E.E.; Bayles, K.W.; Bohach, G.A., Schlievert P. M.,Ohlendorf D. H. Beta toxin catalyzes formation of nucleoprotein matrix in staphylococcal biofilms. Proceedings of the National Academy of Sciences, 107(32): 1440714412, 2010.

Jarraud, S.; Cozon, G.; Vandenesch, F.; Bes, M.; Etienne, J.; Lina, G. Involvement of enterotoxins $\mathrm{G}$ and $\mathrm{I}$ in staphylococcal toxic shock syndrome and staphylococcal scarlet fever. Journal of Clinical Microbiology, 37(8): 2446-2449, 1999.

Jarraud, S.; Peyrat, M.A.; Lim, A.; Tristan, A.; Bes, M.; Mougel, C.; Etienne, J.; Vandenesch, F.; Bonneville, M.; Lina, G. egc, a highly prevalent operon of enterotoxin gene, forms a putative nursery of superantigens in Staphylococcus aureus. The Journal of Immunology, 166(1): 669-677, 2001.

Johns, M.; Khan S.A. Staphylococcal enterotoxin $\mathrm{B}$ gene is associated with a discrete genetic element. Journal of Bacteriology, 170(9): 4033-4039, 1988.

Johnson, G.M.; Lee, D.; Regelmann, W.; Gray, E.; Peters, G.; Quie, P. Interference with granulocyte function by Staphylococcus epidermidis slime. Infection and Immunity, 54(1): 13-20, 1986.

Jolivet-Gougeon, A.; Bonnaure-Mallet, M. Biofilms as a mechanism of bacterial resistance. Drug Discovery Today: Technologies, 11: 49-56, 2014.

Jones, C. Revised structures for the capsular polysaccharides from Staphylococcus aureus Types 5 and 8, components of novel glycoconjugate vaccines. Carbohydrate Research, 340(6): 1097-1106, 2005.

Jönsson, K.; Signäs, C.; Müller, H.P.; Lindberg, M. Two different genes encode fibronectin binding proteins in Staphylococcus aureus. 
European Journal of Biochemistry, 202(3): 1041-1048, 1991.

Kappler, J.; White, J.; Kozono, H.; Clements, J.; Marrack, P. Binding of a soluble alpha beta Tcell receptor to superantigen/major histocompatibility complex ligands. Proceedings of the National Academy of Sciences, 91(18): 8462-8466, 1994.

Karakawa, W.; Vann, W.F. Capsular polysaccharides of Staphylococcus aureus. Seminars in Infectious Diseases, 4: 285-293, 1982.

Katayama, Y.; Baba, T.; Sekine, M.; Fukuda, M.; Hiramatsu, K. Beta-hemolysin promotes skin colonization by Staphylococcus aureus. Journal of Bacteriology, 195(6): 1194-1203, 2013.

Kehoe, M.; Duncan, J.; Foster, T.; Fairweather, N.; Dougan, G. Cloning, expression, and mapping of the Staphylococcus aureus alphahemolysin determinant in Escherichia coli $\mathrm{K}$ 12. Infection and Immunity, 41(3): 11051111, 1983.

Kolata, J.; Bode, L.G.; Holtfreter, S.; Steil, L.; Kusch, H.; Holtfreter, B.; Albrecht, D.; Hecker, M.; Engelmann, S.; van Belkum, A. Distinctive patterns in the human antibody response to Staphylococcus aureus bacteremia in carriers and non-carriers. Proteomics, 11(19): 3914-3927, 2011.

König, W.; Prevost, G. Composition of staphylococcal bi-component toxins determines pathophysiological reactions. Journal of Medical Microbiology, 46(6): 479-485, 1997.

Kumar, R.; Yadav, B.; Anand, S.; Singh, R. Prevalence of adhesin and toxin genes among isolates of Staphylococcus aureus; obtained from mastitic cattle. World Journal of Microbiology and Biotechnology, 27(3): 513-521, 2011.

Lam, J.S.; Macdonald, L.A.; Lam, M.; Duchesne, L.; Southam, G.G. Production and characterization of monoclonal antibodies against serotype strains of Pseudomonas aeruginosa. Infection and Immunity, 55(5): 1051-1057, 1987.

Lamaita, H.; Cerqueira, M.; Carmo, L.; Santos, D.; Penna, C.; Souza, M. Staphylococcus sp. counting and detection of staphylococcal enterotoxins and toxic shock toxin syndrome from cooled raw milk. Arquivo Brasileiro de
Medicina Veterinária e Zootecnia, 57(5): 702-709, 2005.

Lasa, I.; Penadés, J.R. Bap: a family of surface proteins involved in biofilm formation. Research in Microbiology, 157(2): 99-107, 2006.

Le Loir, Y.; Baron, F.; Gautier, M. Staphylococcus aureus and food poisoning. Genetics and Molecular Research, 2(1): 63-76, 2003.

Lee, J.C.; Takeda, S.; Livolsi, P.; Paoletti, L. Effects of in vitro and in vivo growth conditions on expression of type 8 capsular polysaccharide by Staphylococcus aureus. Infection and Immunity, 61(5): 1853-1858, 1993.

Lee, K.; Fitton J.; Wüthrich, K. Nuclear magnetic resonance investigation of the conformation of $\delta$-haemolysin bound to dodecylphosphocholine micelles. Biochimica et Biophysica Acta, 911(2): 144-153, 1987.

Leid, J.G.; Willson, C.J.; Shirtliff, M.E.; Hassett, D.J.; Parsek, M.R.; Jeffers, A.K. The exopolysaccharide alginate protects Pseudomonas aeruginosa biofilm bacteria from IFN- $\gamma$-mediated macrophage killing. The Journal of Immunology, 175(11): 7512$7518,2005$.

Mack, D. Molecular mechanisms of Staphylococcus epidermidis biofilm formation. Journal of Hospital Infection, 43: S113-S125, 1999.

Marr, J.; Lyon, J.; Roberson, J.; Lupher, M.; Davis, W.; Bohach, G. Characterization of novel type $\mathrm{C}$ staphylococcal enterotoxins: biological and evolutionary implications. Infection and Immunity, 61(10): 4254-4262, 1993.

Marrack, P.; Kappler, J. The staphylococcal enterotoxins and their relatives. Science, 248(4956): 705-711, 1990.

Mazmanian, S.; Liu, G., Ton-That H.,Schneewind O. Staphylococcus aureus sortase, an enzyme that anchors surface proteins to the cell wall. Science, 285(5428): 760-763, 1999.

Melchior, M.B.; Vaarkamp, H.; Fink-Gremmels, J. Biofilms: A role in recurrent mastitis infections? The Veterinary Journal, 171(3): 398-407, 2006.

Monday, S.R.; Bohach G.A. Properties of Staphylococcus aureus enterotoxins and toxic shock syndrome-toxin-1. In: Alouf, J.; Freer, J.H. The comprehensive sourcebook of bacterial protein toxins, 1999, p.589-610. 
Moreau, M.; Richards, J.C.; Fournier, J.-M.; Byrd, R.A.; Karakawa, W.W.; Vann, W.F. Structure of the type 5 capsular polysaccharide of Staphylococcus aureus. Carbohydrate Research, 201(2): 285-297, 1990.

Munson, S.H.; Tremaine, M.T.; Betley, M.J.; Welch, R.A. Identification and characterization of staphylococcal enterotoxin types G and I fromStaphylococcus aureus. Infection and Immunity, 66(7): 3337-3348, 1998.

Murthy, S.V.K.N.; Ann, M.M.; Harris, T.M.; Hellerqvist, C.G.; Hash, J.H. The repeating sequence of the capsular polysaccharide of Staphylococcus aureus M. Carbohydrate Research, 117: 113-123, 1983.

Navarre, W.; Schneewind, O. Proteolytic cleavage and cell wall anchoring at the LPXTG motif of surface proteins in gram-positive bacteria. Molecular Microbiology, 14(1): 115-121, 1994.

Ní Eidhin, D.; Perkins, S.; Francois, P.; Vaudaux, P.; Höök, M.; Foster, T.J. Clumping factor B (ClfB), a new surface-located fibrinogenbinding adhesin of Staphylococcus aureus. Molecular Microbiology, 30(2): 245-257, 1998.

Niemann, S.; Spehr, N.; Van Aken, H.; Morgenstern, E.; Peters, G., Herrmann, M., Kehrel, B.E. Soluble fibrin is the main mediator of Staphylococcus aureus adhesion to platelets. Circulation, 110(2): 193-200, 2004.

Novick, R.P. Autoinduction and signal transduction in the regulation of staphylococcal virulence. Molecular Microbiology, 48(6): 1429-1449, 2003.

O'Neill, E.; Pozzi, C.; Houston, P.; Humphreys, H.; Robinson, D.A.; Loughman, A.; Foster T. J.; O'Gara, J.P. A novel Staphylococcus aureus biofilm phenotype mediated by the fibronectin-binding proteins, FnBPA and FnBPB. Journal of Bacteriology, 190(11): 3835-3850, 2008.

O'Riordan, K.; Lee J.C. Staphylococcus aureus capsular polysaccharides. Clinical Microbiology Reviews, 17(1): 218-234, 2004.

Oliveira, M.; Bexiga, R.; Nunes, S.F.; Carneiro, C.; Cavaco, L.M.; Bernardo, F.; Vilela, C.L. Biofilm-forming ability profiling of Staphylococcus aureus and Staphylococcus epidermidis mastitis isolates. Veterinary Microbiology, 118(1-2): 133-140, 2006.

Ono, H.K.; Sato'o, Y.; Narita, K.; Naito, I.; Hirose, S.; Hisatsune, J.; Asano, K.; Hu, D.L.; Omoe, K.; Sugai, M.; Nakane, A. Identification and characterization of a Novel Staphylococcal Emetic Toxin. Applied and Environmental Microbiology, 81(20): 7034-7040, 2015.

Ote, I.; Taminiau, B.; Duprez, J.-N.; Dizier, I.; Mainil, J.G. Genotypic characterization by polymerase chain reaction of Staphylococcus aureus isolates associated with bovine mastitis. Veterinary Microbiology, 153(34): 285-292, 2011.

Patti, J.M.; Allen, B.L.; McGavin, M.J.; Hook, M. MSCRAMM-mediated adherence of microorganisms to host tissues. Annual Review of Microbiology, 48(1): 585-617, 1994.

Peacock, S.J.; Moore, C.E.; Justice, A.; Kantzanou, M.; Story, L.; Mackie, K.; O'Neill, G.; Day, N.P. Virulent combinations of adhesin and toxin genes in natural populations of Staphylococcus aureus. Infection and Immunity, 70(9): 4987-4996, 2002.

Petersson, K.; Håkansson, M.; Nilsson, H.; Forsberg, G.; Svensson, L.A.; Liljas, A.; Walse, B. Crystal structure of a superantigen bound to MHC class II displays zinc and peptide dependence. The EMBO Journal, 20(13): 3306-3312, 2001

Planchon, S.; Gaillard-Martinie, B.; DordetFrisoni, E.; Bellon-Fontaine, M.; Leroy, S.; Labadie, J.; Hébraud, M.; Talon, R. Formation of biofilm by Staphylococcus xylosus. International Journal of Food Microbiology, 109(1): 88-96, 2006.

Prevost, G.; Cribier, B.; Couppie, P.; Petiau, P.; Supersac, G.; Finck-Barbancon, V.; Monteil, H.; Piemont, Y. Panton-Valentine leucocidin and gamma-hemolysin from Staphylococcus aureus ATCC 49775 are encoded by distinct genetic loci and have different biological activities. Infection and Immunity, 63(10): 4121-4129, 1995.

Projan, S.J.; Kornblum, J.; Kreiswirth, B.; Moghazeh, S.L.; Eisner, W.; Novick, R.P.

Nucleotide sequence: the beta-hemolysin gene of Staphylococcus aureus. Nucleic Acids Research, 17(8): 3305, 1989.

Rall, V.L.M.; Miranda, E.S.; Castilho, I.G.; Camargo, C.H.; Langoni, H.; Guimarães, F.F.; Araújo Júnior, J.P.; Fernandes Júnior, A. 
Diversity of Staphylococcus species and prevalence of enterotoxin genes isolated from milk of healthy cows and cows with subclinical mastitis. Journal of Dairy Science, 97(2): 829-837, 2014.

Recsei, P.; Kreiswirth, B.; O'Reilly, M.; Schlievert, P.; Gruss, A.; Novick, R.P. Regulation of exoprotein gene expression in Staphylococcus aureus by agr. Molecular Genetics and Genomics, 202(1): 58-61, 1986.

Rellahan, B.L.; Jones, L.A.; Kruisbeek, A.M.; Fry, A.; Matis, L. In vivo induction of anergy in peripheral $\mathrm{V}$ beta $8+\mathrm{T}$ cells by staphylococcal enterotoxin B. The Journal of Experimental Medicine, 172(4): 1091-1100, 1990.

Ren, K.; Bannan, J.D.; Pancholi, V.; Cheung, A.L.; Robbins, J.C.; Fischetti, V.A.; Zabriskie, J.B. Characterization and biological properties of a new staphylococcal exotoxin. The Journal of Experimental Medicine, 180(5): 1675-1683, 1994.

Sá, M.E.P.; Cunha, M.L.R.S.; Elias, A.O.; Victória, C.; Langoni, H. Importância do Staphylococcus aureus nas mastites subclínicas: pesquisa de enterotoxinas e toxina do choque tóxico, ea relação com a contagem de células somáticas. Brazilian Journal of Veterinary Research and Animal Science, 41(5): 320-326, 2004.

Salasia, S.I.O.; Tato, S.; Sugiyono, N.; Ariyanti, D.; Prabawati, F. Genotypic characterization of Staphylococcus aureus isolated from bovines, humans, and food in Indonesia. Journal of Veterinary Science, 12(4): 353361, 2011.

Senger, A.E.V.; Bizani, D. Pesquisa de Staphylococcus aureus em queijo minas frescal, produzido de forma artesanal e industrial, comercializado na cidade de Canoas/RS, Brasil. Revista de Ciências Ambientais, 5(2): 25-42, 2011.

Shafer, W.M.; Iandolo, J.J. Chromosomal locus for staphylococcal enterotoxin B. Infection and Immunity, 20(1): 273-278, 1978.

Shalita, Z.; Hertman, I.; Sarid, S. Isolation and characterization of a plasmid involved with enterotoxin B production in Staphylococcus aureus. Journal of Bacteriology, 129(1): 317-325, 1977.

Shanks, R.M.; Meehl, M.A.; Brothers, K.M.; Martinez, R.M.; Donegan, N.P.; Graber, M.L.; Cheung, A.L.; O'Toole, G.A. Genetic evidence for an alternative citrate-dependent biofilm formation pathway in Staphylococcus aureus that is dependent on fibronectin binding proteins and the GraRS twocomponent regulatory system. Infection and Immunity, 76(6): 2469-2477, 2008.

Shinji, H.; Yosizawa, Y.; Tajima, A.; Iwase, T.; Sugimoto, S.; Seki, K.; Mizunoe, Y. Role of fibronectin-binding proteins $\mathrm{A}$ and $\mathrm{B}$ in in vitro cellular infections and in vivo septic infections by Staphylococcus aureus. Infection and Immunity, 79(6): 2215-2223, 2011.

Signäs, C.; Raucci, G.; Jönsson, K.; Lindgren, P.; Anantharamaiah, G.; Höök, M.; Lindberg, M. Nucleotide sequence of the gene for a fibronectin-binding protein from Staphylococcus aureus: use of this peptide sequence in the synthesis of biologically active peptides. Proceedings of the National Academy of Sciences, 86(2): 699-703, 1989.

Siqueira, J.; Speeg-Schatz, C.; Freitas, F.; Sahel, J.; Monteil, H.; Prevost, G. Channel-forming leucotoxins from Staphylococcus aureus cause severe inflammatory reactions in a rabbit eye model. Journal of Medical Microbiology, 46(6): 486-494, 1997.

Solano, C.; Echeverz M.; Lasa I. Biofilm dispersion and quorum sensing. Current Opinion in Microbiology, 18: 96-104, 2014.

Sompolinsky, D.; Samra, Z.; Karakawa, W.; Vann, W.; Schneerson, R.; Malik, Z. Encapsulation and capsular types in isolates of Staphylococcus aureus from different sources and relationship to phage types. Journal of Clinical Microbiology, 22(5): 828-834, 1985. Song, L.; Hobaugh, M.R.; Shustak, C.; Cheley, S.; Bayley, H.; Gouaux, J.E. Structure of staphylococcal alpha-hemolysin, a heptameric transmembrane pore. Science, 274(5294): 1859-1866, 1996.

Speziale, P.; Pietrocola, G.; Rindi, S.; Provenzano, M.; Provenza, G.; Di, Poto A.; Visai, L.; Arciola, C.R. Structural and functional role of Staphylococcus aureus surface components recognizing adhesive matrix molecules of the host. Future Microbiology, 4(10): 13371352, 2009.

Stewart, P.S. Mechanisms of antibiotic resistance in bacterial biofilms. International Journal of Medical Microbiology, 292(2): 107-113, 2002.

Stoodley, P.; Sauer, K.; Davies, D.; Costerton, J.W. Biofilms as complex differentiated 
communities. Annual Review of Microbiology, 56(1): 187-209, 2002.

Stringfellow, W.; Dassy, B.; Lieb, M.; Fournier J. Staphylococcus aureus growth and type 5 capsular polysaccharide production in synthetic media. Applied and Environmental Microbiology, 57(2): 618$621,1991$.

Su, Y.-C.; Wong, A. Identification and purification of a new staphylococcal enterotoxin, $\mathrm{H}$. Applied and Environmental Microbiology, 61(4): 1438-1443, 1995.

Sutra, L.; Rainard, P.; Poutrel, B. Phagocytosis of mastitis isolates of Staphylococcus aureus and expression of type 5 capsular polysaccharide are influenced by growth in the presence of milk. Journal of Clinical Microbiology, 28(10): 2253-2258, 1990.

Tajima, A.; Iwase, T.; Shinji, H.; Seki, K.; Mizunoe, Y. Inhibition of endothelial interleukin-8 production and neutrophil transmigration by Staphylococcus aureus beta-hemolysin. Infection and Immunity, 77(1): 327-334, 2009.

Thakker, M.; Park, J.-S.; Carey, V.; Lee, J.C. Staphylococcus aureus serotype 5 capsular polysaccharide is antiphagocytic and enhances bacterial virulence in a murine bacteremia model. Infection and Immunity, 66(11): 5183-5189, 1998.

Thurlow, L.R.; Hanke, M.L.; Fritz, T.; Angle, A.; Aldrich, A.; Williams, S.H.; Engebretsen, I.L.; Bayles, K.W.; Horswill, A.R.; Kielian T. Staphylococcus aureus biofilms prevent macrophage phagocytosis and attenuate inflammation in vivo. The Journal of Immunology, 186(11): 6585-6596, 2011.

Tormo, M.A.; Knecht, E.; Götz, F.; Lasa, I.; Penades, J.R. Bap-dependent biofilm formation by pathogenic species of Staphylococcus: evidence of horizontal gene transfer? Microbiology, 151(7): 2465-2475, 2005.

Torres, V.J.; Pishchany, G.; Humayun, M.; Schneewind, O.; Skaar, E. P. Staphylococcus aureus $\mathrm{IsdB}$ is a hemoglobin receptor required for heme iron utilization. Journal of Bacteriology, 188(24): 8421-8429, 2006.

Tremaine, M.; Brockman, D.; Betley, M. Staphylococcal enterotoxin A gene (sea) expression is not affected by the accessory gene regulator (agr). Infection and Immunity, 61(1): 356-359, 1993.
Trengove, N.J.; Langton, S.R.; Stacey, M.C. Biochemical analysis of wound fluid from nonhealing and healing chronic leg ulcers. Wound Repair and Regeneration, 4(2): 234-239, 1996.

Tuchscherr, L.P.N.; Buzzola F.R.; Alvarez L.P.; Caccuri R.L.; Lee J.C.; Sordelli D.O. Capsulenegative Staphylococcus aureus induces chronic experimental mastitis in mice. Infection and Immunity, 73(12): 7932-7937, 2005.

Tweten, R.; Christianson K.; Iandolo J. Transport and processing of staphylococcal alpha-toxin. Journal of Bacteriology, 156(2): 524-528, 1983.

Van Leeuwen, W.B.; Melles, D.C.; Alaidan, A.; Al-Ahdal, M.; Boelens, H.A.; Snijders, S.V.; Wertheim, H.; van Duijkeren, E.; Peeters, J.K.; van der Spek, P.J.; Gorkink, R.; Simons, G.; Verbrugh, H.A.; van Belkum, A. Hostand tissue-specific pathogenic traits of Staphylococcus aureus. Journal of bacteriology, 187(13): 4584-4591, 2005.

Veronesi, R.; Focaccia, R. Tratado de infectologia. v. 2. São Paulo: Atheneu; 2009, p.1351.

Vuong, C.; Saenz, H.L.; Götz, F.; Otto, M. Impact of the agr quorum-sensing system on adherence to polystyrene in Staphylococcus aureus. The Journal of Infectious Diseases, 182(6): 1688-1693, 2000.

Walev, I.; Weller, U.; Strauch, S.; Foster, T.; Bhakdi, S. Selective killing of human monocytes and cytokine release provoked by sphingomyelinase (beta-toxin) of Staphylococcus aureus. Infection and Immunity, 64(8): 2974-2979, 1996.

Waryah, C.B.; Gogoi-Tiwari, J.; Wells, K.; Costantino, P.; Al-Salami, H.; Sunagar, R.; Isloor, S.; Hegde, N.; Richmond, P.; Mukkur, T. Serological versus molecular typing of surface-associated immune evading polysaccharide antigens-based phenotypes of Staphylococcus aureus. Journal of Medical Microbiology, 63(11): 1427-1431, 2014.

Wilke, G.A.;Wardenburg, J.B. Role of a disintegrin and metalloprotease 10 in Staphylococcus aureus $\alpha$-hemolysin-mediated cellular injury. Proceedings of the National Academy of Sciences, 107(30): 13473-13478, 2010.

Wilson, G.J.; Seo, K.S.; Cartwright, R.A.; Connelley, T.; Chuang-Smith, O.N.; Merriman, J. A.; Guinane, C.M.; Park, J.Y.; 
Bohach, G.A.; Schlievert, P.M.A novel core genome-encoded superantigen contributes to lethality of community-associated MRSA necrotizing pneumonia. PLoS pathogens, 7(10): e1002271, 2011.

Yarwood, J.M.; Schlievert, P.M. Quorum sensing in Staphylococcus infections. The Journal of Clinical Investigation, 112(11): 1620-1625, 2003.

Yasuda, H.; Ajiki, Y.; Aoyama, J.; Yokota, T. Interaction between human polymorphonuclear leucocytes and bacteria released from in-vitro bacterial biofilm models.
Journal of Medical Microbiology, 41(5): 359-367, 1994.

Zecconi, A.; Scali, F. Staphylococcus aureus virulence factors in evasion from innate immune defenses in human and animal diseases. Immunology Letters, 150(1-2): 12 22, 2013.

Zhang, S.; Iandolo, J.J.; Stewart, G.C. The enterotoxin D plasmid of Staphylococcus aureus encodes a second enterotoxin determinant (sej). FEMS microbiology letters, 168(2): 227-233, 1998. 